\title{
A CONCEPÇÃO DE ORGANIZAÇÃO DO PROCESSO EDUCATIVO NA EDUCAÇÃO PROFISSIONAL NA MODALIDADE EAD
}

\author{
Karolina da Silva Cabral ${ }^{1}$ \\ Clóvis Nicanor Kassick²
}

\begin{abstract}
RESUMO
Objetivando compreender a organização do processo educativo na educação profissional de nível médio na modalidade a distância e partindo do pressuposto que uma aprendizagem significativa caracteriza-se e resulta em uma aprendizagem duradoura, sustentou-se a hipótese de que os cursos profissionalizantes de nível médio na modalidade EaD proporcionam uma aprendizagem efetiva, desde que partindo de um alinhamento entre a organização do processo pedagógico com suas bases teóricas e possuam foco na formação com qualidade técnica e humanística/cidadã de seu alunado. A relevância da pesquisa se dá pela expansão prevista no Plano Nacional de Educação, Lei no 13.005/2014. O objeto deste estudo foi o curso técnico em Automação Industrial na modalidade EaD do SENAI de Santa Catarina, para perceber se as estratégias de ensino nele apontadas alinhavam-se aos pressupostos teóricos pretendidos.
\end{abstract}

Palavras-chave: Organização do Processo Educativo; Educação Profissional; Ensino a Distância; Aprendizagem Significativa.

\section{THE ORGANIZATIONAL CONCEPT OF THE EDUCATIONAL PROCESS IN THE PROFESSIONAL EDUCATION IN THE DISTANCE LEARNING MODULE}

\begin{abstract}
With the objective of comprehending the organization of the educational process in the high school professional education in a distance learning module, and assuming that a significant learning process results and feature in a lasting learning engagement, we support the hypothesis the professional courses in the high school in the distance learning module allows an effective learning, if it aligns the organization of the pedagogical process with its theoretical bases and focus in the graduation of its students with technical and humane qualities. The relevance of this research is given by the expansion proposed in the National Educational Plan, Law n. 13.005/2014. This research's object was the SENAl's technical course level in Industrial Automation in the distance learning module in Santa Catarina, to notice if the learning strategies in this course aligned the intended theoretical assumptions.
\end{abstract}

Keywords: The educational process organization; Professional education; Distance learning; Meaningful learning.

\section{EL PROCESO DE DISEÑO DE LA ORGANIZACIÓN EDUCATIVA EN LA FORMACIÓN PROFESIONAL EN TIPO EDUCACIÓN A DISTANCIA}

\footnotetext{
${ }^{1}$ Graduada em Pedagogia, pós-graduada em Metodologia e Prática Interdisciplinar do Ensino e Mestre em Educação. Atualmente Coordenadora Pedagógica no Senai/SC de Tubarão. E-mail: <karol0506@gmail.com>

2 Doutorado em Educação pela Universidade Estadual de Campinas-UNICAMP (2001). Professor Adjunto II aposentado da UFSC, atualmente é professor da Universidade do Sul de Santa Catarina-UNISUL, no Curso de Pedagogia e no Programa de Pós-Graduação-Mestrado em Educação. É pesquisador do grupo GTMC-UFSC, na pesquisa: Elaboração de Currículos Referência para os Cursos Técnicos da Escola Técnica Aberta do Brasil/ e-Tec Brasil, do E-TEC/SETEC/MEC. E-mail: <kassickclovis@gmail.com>
} 
Karolina da Silva Cabral Clóvis Nicanor Kassick

\section{RESUMEN}

Con el objetivo de comprender la organización del proceso educativo en la formación profesional de grado medio a distancia, en el supuesto de que un aprendizaje significativo caracteriza y da lugar a la formación permanente, apoyamos la hipótesis de que la formación profesional de nivel medio en modalidad de educación a distancia puede proporcionar un aprendizaje efectivo, desde un alineamiento entre la organización del proceso pedagógico con su base teórica y que tenga enfoque en la formación con calidad técnica y humana/ciudadana de sus alumnos. La relevancia de la investigación se queda por la ampliación prevista en el Plan Nacional de Educación, la Ley $n^{\circ}$ 13.005/2014. El objeto de este estudio fue el curso técnico en automatización industrial, en la modalidad de educación a distancia del SENAI de Santa Catarina, al darse cuenta de que las estrategias de enseñanza se señalaron, se alinearon los supuestos teóricos previstos.

Palabras-clave: Organización del proceso educativo; Educación profesional; Aprendizaje a distancia; Aprendizaje significativo.

\section{INTRODUÇÃO}

O Plano Nacional de Educação (PNE), Lei no 13.005/2014, possui como 11a meta "triplicar as matrículas da educação profissional técnica de nível médio, assegurando a qualidade da oferta e pelo menos $50 \%$ (cinquenta por cento) da expansão no segmento público" (OBSERVATÓRIO PNE, 2015, s/p).

A expansão da $\operatorname{EaD}$ no Brasil fica evidente quando se visualiza o número de matrículas e as diferentes instituições que se utilizam dessa modalidade de ensino. Conforme informações da Associação Brasileira de Educação a Distância (ABED 2015), o número de estudantes na EaD, no período de 2005 a 2008, era de 2,5 milhões, de acordo com levantamento realizado diretamente com as instituições participantes.

Percebe-se que o ritmo da vida moderna exige cada vez mais a flexibilização e otimização do tempo, fazendo uso especialmente dos recursos tecnológicos disponíveis, destacando-se os de comunicação.

A EaD é parte integrante das atuais políticas públicas brasileiras, como especifica Gomes (2015, p. 52):

Exemplos de políticas públicas atuais voltadas para a EaD no Brasil são: - o programa de ampliação da oferta do ensino superior gratuito e de qualidade no Brasil; - o Programa de Formação Inicial para Professores do Ensino Fundamental e Médio, o PRÓ-LICENCIATURA, que é um curso do MEC destinado a professores que não possuem a habilitação mínima legalmente 
Karolina da Silva Cabral Clóvis Nicanor Kassick

exigida, mas encontram-se lecionando no Ensino Fundamental ou no Ensino Médio; projetos envolvendo a produção de conteúdos educacionais digitais multimídia nas áreas de Matemática, Língua Portuguesa, Física, Química e Biologia do Ensino Médio e incentivando o uso de novas tecnologias nas escolas.

Partindo do entendimento de que as políticas públicas traduzem seus propósitos através de programas e ações, percebem-se, nos atuais planos de governo, propostas de ampliação do atendimento da educação à população. Para isso, a modalidade EaD é apontada como estratégia, e tem sido utilizada como tal para o alcance da meta 11 do PNE. O desafio, contudo, tem sido o de assegurar a qualidade da educação diante da expansão de seu oferecimento.

Isso é ainda mais evidente em um país de dimensões continentais como o Brasil, razão pela qual a EaD tornou-se, nas últimas décadas, uma ferramenta indispensável para ajudar a contornar os problemas enfrentados pelo ensino formal. Regiões de difícil acesso, florestas, rios e estradas sem asfalto e sem nenhuma condição de tráfego transformam-se em barreiras naturais para milhares de estudantes, e muitos nem começam a estudar por falta de oferta de escolas. Entre aqueles que conseguem, vários abandonam a instituição escolar, não por falta de vontade, mas pelas dificuldades encontradas para chegar a uma escola distante, o que representa um obstáculo quase intransponível para um ensino de qualidade.

Para o alcance da meta 11 do PNE foi destacada, como uma das estratégias comprometidas com a qualidade, a pretensão de "[...] institucionalizar sistema de avaliação da qualidade da educação profissional técnica de nível médio das redes escolares públicas e privadas" (OBSERVATÓRIO PNE, 2015, s/p).

Nesta perspectiva, o professor é fortemente atingido pela introdução das tecnologias de comunicação em seu exercício profissional. O novo fazer pedagógico exige o domínio de tecnologias educacionais.

Considerando que o ensino presencial também tem feito uso das novas tecnologias, é essencial que o professor busque qualificar-se e dominar este conhecimento para que, então, somado ao domínio do conteúdo específico, possa ser considerado um profissional capaz e apto a desenvolver seu papel.

No entanto, ainda hoje, encontra-se um elevado número de professores sem habilitação lecionando nas escolas brasileiras. A desvalorização do profissional da educação 
tem feito com que os jovens busquem outras carreiras e deixem de almejar a docência como profissão e possibilidade de construção de carreira.

É preciso considerar, ainda, que o profissional da educação, além da formação inicial, deve estar em constante processo de atualização, tendo em vista as sempre novas demandas sociais. Nesse sentido, o professor não pode deixar-se levar pelo processo de alienação, próprio da sociedade em que se vive, para não comprometer o seu trabalho e, por decorrência, a formação de seus alunos.

A alienação, por exemplo, do operário da indústria automobilística não compromete a qualificação do automóvel que ele contribui para construir, mas a alienação do trabalho do professor interfere na qualidade do produto de seu trabalho. $O$ trabalho educativo pressupõe o homem frente a outro homem de quem não pode estar estranho (alienado), fundando-se numa relação que é por natureza inter-pessoal [sic] e mediada pelas apropriações e objetivações desses homens (MARTINS, 2007, p. 5).

Mesmo na educação presencial já é possível observar um número significativo de cursos que possuem algum percentual de sua carga horária a distância, além de disciplinas presenciais que fazem uso de plataformas eletrônicas como apoio para suas aulas.

O art. 10 da Portaria no 4.059, de 10 de dezembro de 2004, dispõe que:

As instituições de ensino superior poderão introduzir, na organização pedagógica e curricular de seus cursos superiores reconhecidos, a oferta de disciplinas integrantes do currículo que utilizem modalidade semi-presencial, com base no art. 81 da lei n. 9.394, de 1.996, e no disposto nesta portaria [...] $\S 2$ ㅇ. Poderão ser ofertadas as disciplinas referidas no caput, integral ou parcialmente, desde que esta oferta não ultrapasse $20 \%$ (vinte por cento) da carga horária total do curso (BRASIL, 2015).

Diante desse cenário e das constatações realizadas, faz-se necessário questionar sobre como se deve organizar o processo pedagógico da educação em geral e, em especial, da educação profissional na modalidade $\mathrm{EaD}$, para que dele resulte uma aprendizagem significativa, e quais bases teóricas são capazes de assegura-las.

Para tanto, partiu-se do pressuposto de que uma aprendizagem significativa caracteriza-se e resulta em uma aprendizagem duradoura, ou seja, o aluno não esquece o que aprendeu após a avaliação ou depois de curto espaço de tempo. Ao contrário, o processo de 
aprendizagem fica registrado de tal forma que, sempre que a pessoa é colocada diante de determinada situação, ela consegue reconstruir o processo de construção da resolução daquela situação-problema em particular, readequando-a para a solução da nova.

Como referência do tema aprendizagem significativa, recorre-se aos conceitos formulados pelo norte-americano Ausubel, citado por Pelizzari, quando afirma que:

Quando o conteúdo escolar a ser aprendido não consegue ligar-se a algo já conhecido, ocorre o que Ausubel chama de aprendizagem mecânica, ou seja, quando as novas informações são aprendidas sem interagir com conceitos relevantes existentes na estrutura cognitiva. Assim, a pessoa decora fórmulas, leis, mas esquece após a avaliação (AUSUBEL apud PELIZZARI et al., 2002, p. 38).

A aprendizagem significativa baseia-se em uma prática pedagógica construída a partir de situações que sejam familiares, que evoquem conhecimentos anteriores dos alunos para que sirvam de elo para um novo conhecimento, capaz e suficiente para a resolução da situação-problema vivida e que se dá pela (re)descoberta do aluno, pela sua conclusão a respeito do objeto problematizado.

De acordo com Pelizzari et al. (2002, p. 41),

Na sua teoria, Ausubel apresenta uma aprendizagem que tenha como ambiente uma comunicação eficaz, que respeite e conduza o aluno a imaginar-se como parte integrante desse novo conhecimento através de elos, de termos familiares a ele. Através da palavra, o educador pode diminuir a distância entre a teoria e a prática na escola, capacitando-se de uma linguagem que ao mesmo tempo desafie e leve o aluno a refletir e sonhar, conhecendo a sua realidade e os seus anseios.

Para proporcionar a aprendizagem significativa, segundo este referencial, cabe ao professor prever estratégias de ensino que instiguem a busca por solução de problemas, análise de estudos de casos, elaboração de projetos, desenvolvimento de mapas conceituais, dentre outras que possam evidenciar a intenção de uma prática pedagógica inclinada ao desenvolvimento de uma aprendizagem significativa.

Nesta perspectiva, para o levantamento de dados desta investigação, buscou-se apoio em obras bibliográficas, documentos oficiais (legislações educacionais), aplicação de questionários a coordenadores de cursos e análise de planos de ensino de quatro disciplinas 
do curso técnico em Automação Industrial, na modalidade EAD, do SENAI de Santa Catarina, para perceber se as estratégias de ensino neles apontadas alinhavam-se aos pressupostos teóricos pretendidos, no sentido de favorecer uma aprendizagem significativa.

\section{EAD E EDUCAÇÃO PROFISSIONAL NO BRASIL}

No Brasil, há indícios da EaD desde o início do século XX, de acordo com Alves (2009, p. 9), "as pesquisas realizadas em diversas fontes mostram que pouco antes de 1900, já existiam anúncios de jornais de circulação no Rio de Janeiro oferecendo cursos profissionalizantes por correspondência", na sua maioria cursos de datilografia oferecidos por professores particulares e não por instituições de ensino.

Os números da EaD no Brasil podem ser consultados no site da $A B E D$, que tem disponibilizado anualmente informações a respeito dos números de matrículas, cursos, entre outras informações.

A respeito das matrículas, o Relatório Analítico da Aprendizagem a Distância no Brasil apresenta os seguintes números:

Em 2014, os cursos de EAD somaram 3.868.706 matrículas, com 519.839 (13\%) nos cursos regulamentados totalmente a distância, 476.484 (12\%) nos cursos regulamentados semipresenciais ou disciplinas EAD de cursos presenciais e 2.872 .383 (75\%) nos cursos livres. A média geral foi de 154 matrículas por curso e de 16.053 matrículas por instituição formadora (ABED, 2015, p. 60).

É importante lembrar que a relação professor-aluno e o processo de ensinoaprendizagem nesta modalidade também sofreram alterações com o passar dos anos e com o avanço tecnológico, pois, cada vez mais diversificados, os canais de comunicação permitiram uma mudança na postura do professor em relação ao aluno, visto que, até então, consideravase que o professor ensinava e o aluno aprendia. 
Karolina da Silva Cabral Clóvis Nicanor Kassick

Sobre a educação profissional e a utilização da EaD, é essencial falar a respeito da Rede e-Tec Brasil ${ }^{3}$, que foi lançada em 2007, com o intuito de desenvolver a educação profissional e tecnológica na modalidade EaD, ampliando e democratizando a oferta e o acesso à educação profissional pública e gratuita no país.

Os programas Rede e-Tec Brasil e PRONATEC têm seus objetivos e metas ratificados no PNE, especificamente na meta 11, conforme já o afirmamos, ao estabelecer como objetivo "triplicar as matrículas da educação profissional técnica de nível médio, assegurando a qualidade da oferta e pelo menos $50 \%$ (cinquenta por cento) da expansão no segmento público", sendo parte das estratégias elencadas para o alcance da referida meta, entre outras, o que afirma o item 11.3: “Fomentar a expansão da oferta de educação profissional técnica de nível médio na modalidade de educação a distância, com a finalidade de ampliar a oferta e democratizar o acesso à educação profissional pública e gratuita, assegurado padrão de qualidade" (BRASIL, 2010, grifo nosso).

Entretanto, é oportuno considerar que ainda são poucos os pesquisadores debruçados sobre esta temática; mesmo assim, os resultados já alcançados apresentam certa expressividade e representam avanços significativos, contribuindo para a melhoria do processo educativo na modalidade a distância como, por exemplo, o relatório Currículo de Referência para o Sistema e-Tec Brasil: uma construção coletiva (2011). Segundo seus autores:

A partir dos resultados obtidos pelo GTMC $/$ UFSC $^{5} / 2009$, foi possível sugerir algumas alternativas de gestão pedagógica para resolver o problema da dispersão dos cursos e da produção de materiais do Sistema e-Tec Brasil. Uma delas, para médio e longo prazo, foi a recomendação de elaborar um Currículo Referência para o Sistema e-Tec Brasil partindo-se da organização de uma Matriz Curricular de Referência para cada tipo de curso, por Eixo Tecnológico (CATAPAN; KASSICK; OTERO, 2011, p. 8).

A expansão é fato e a preocupação com a qualidade é latente e faz parte dos mais diferentes grupos envolvidos, sejam professores, alunos, instituições, governo, entre outros.

\footnotetext{
${ }^{3}$ A Rede e-Tec Brasil posteriormente foi integrada ao Programa Nacional de Acesso ao Ensino Técnico e Emprego (PRONATEC) (Lei no 12.513, de 26 de outubro de 2011), que possui outros projetos e ações de assistência técnica e financeira com o objetivo de garantir o acesso à educação profissional e tecnológica.

${ }^{4}$ Grupo de Trabalho Matriz Curricular.

${ }^{5}$ Universidade Federal de Santa Catarina.
} 
Por esta razão, mais pesquisas são necessárias para que o ensino na modalidade EaD possa continuar se expandindo sem perder o foco na qualidade do ensino.

\section{O CURSO TÉCNICO DE NÍVEL MÉDIO EM AUTOMAÇÃO INDUSTRIAL NA MODALIDADE EAD}

O SENAI trabalha com educação profissional desde o ano de sua criação, 1942, como registra a história da educação profissional no Brasil. A instituição tem procurado adaptar-se às novas tecnologias e flexibilizar, dessa forma, novos meios de aprendizagem, assim como oportunizar o ingresso ao mundo do trabalho daqueles que necessitam de uma qualificação.

O curso técnico em Automação Industrial na modalidade EaD passou a ser oferecido pelo SENAI em Santa Catarina no ano de 2013, com uma carga horária de 1.754h, e de forma a permitir ao estudante, como descrito pela instituição, "atuar nas áreas de desenvolvimento e na implantação de projetos de sistemas de controle e automação, bem como prestar serviços de fiscalização e manutenção desses sistemas de acordo com normas técnicas de segurança e de preservação ambiental" (SENAI, 2015b, s/p). O curso possui, como público-alvo, os alunos que estão cursando o 2ำ ano do Ensino Médio ou os que já o concluíram.

Quanto à organização e oferta de cursos técnicos, está prevista no Decreto no 5.154, de 23 de julho de 2004:

Art. 4ำ A educação profissional técnica de nível médio, nos termos dispostos no $\S 2^{\circ}$ do art. 36 , art. 40 e parágrafo único do art. 41 da Lei $n^{\circ} 9.394$, de 1996, será desenvolvida de forma articulada com o ensino médio, observados:

I - os objetivos contidos nas diretrizes curriculares nacionais definidas pelo Conselho Nacional de Educação;

II - as normas complementares dos respectivos sistemas de ensino; e

III - as exigências de cada instituição de ensino, nos termos de seu projeto pedagógico.

$\S 1$ 1 A articulação entre a educação profissional técnica de nível médio e o ensino médio dar-se-á de forma:

I - integrada, oferecida somente a quem já tenha concluído o ensino fundamental, sendo o curso planejado de modo a conduzir o aluno à habilitação profissional técnica de nível médio, na mesma instituição de ensino, contando com matrícula única para cada aluno; 
II - concomitante, oferecida somente a quem já tenha concluído o ensino fundamental ou esteja cursando o ensino médio, na qual a complementaridade entre a educação profissional técnica de nível médio e o ensino médio pressupõe a existência de matrículas distintas para cada curso, podendo ocorrer:

a) na mesma instituição de ensino, aproveitando-se as oportunidades educacionais disponíveis;

b) em instituições de ensino distintas, aproveitando-se as oportunidades educacionais disponíveis; ou

c) em instituições de ensino distintas, mediante convênios de intercomplementaridade, visando o planejamento e o desenvolvimento de projetos pedagógicos unificados;

III - subsequente, oferecida somente a quem já tenha concluído o ensino médio (BRASIL, 2004).

Tendo por base estes pressupostos e condições de ingresso estabelecidos pela instituição, o curso analisado enquadra-se como curso técnico concomitante e subsequente.

Além dos pré-requisitos mencionados anteriormente, os alunos, para ingressarem no curso na modalidade EaD, necessitam apresentar documentos pessoais legais e:

\section{$[\ldots]$}

c) Ter acesso à Internet: $O$ candidato é responsável pelos meios de acesso à Internet, para participação nas aulas online (acesso aproximado de 20 horas semanais) durante o período do curso. d) Ter disponibilidade para participar dos encontros presenciais, aulas práticas em laboratório ou visitas técnicas (SENAI, 2015a).

Essa modalidade de estudo prevê encontros presenciais com quatro horas de duração, agendados em calendários específicos do curso e, na maioria das vezes, aos sábados.

O curso oferecido pelo SENAI/SC em Automação Industrial EaD possui carga horária de 1.360h de curso, além de mais $100 \mathrm{~h}$ de Trabalho de Conclusão de Curso (TCC) ou 300h de estágio. Logo, é possível observar, a partir desses números, que a duração do curso é superior ao mínimo exigido por lei, que é de 1.200 horas.

Em relação à organização curricular, o curso, na modalidade EaD, prevê em seu projeto: “O itinerário formativo [...] estruturado em 4 (quatro) módulos: 1 (um) básico, 1 (um) introdutório e 2 (dois) módulos específicos, num total de 1.360 horas, acompanhado de Estágio (300 horas) ou TCC (100 horas)" (SENAI, 2012). 
Para atingir tais objetivos, o SENAl faz uso da chamada Situação de Aprendizagem, que a instituição define como

[...] um conjunto de ações que planejadas pedagogicamente favorecem aprendizagens significativas, por meio da utilização de Estratégias de Aprendizagem Desafiadoras (situação-problema, estudos de caso, projeto e pesquisa aplicada) diferentes estratégias de ensino (exposição dialogada ou mediada, demonstração, estudo dirigido, visitas técnicas, entre outras) (SENAI, 2013, p. 121).

A Situação de Aprendizagem constitui-se em um documento complementar ao plano de ensino, no qual há um detalhamento das atividades propostas:

As Situações de Aprendizagem devem ser contextualizadas, ter valor sociocultural, evocar saberes, estimular criatividade e mobilizar a solução de problemas, a testagem de hipóteses e a tomada de decisão, desenvolvendo no aluno as capacidades que sustentam as competências definidas no Perfil Profissional (SENAI, 2013, p. 121).

O docente é responsável pela elaboração da Situação de Aprendizagem e pelo preenchimento do formulário. Esse profissional deve indicar, no formulário, os Fundamentos, Capacidades e Conhecimentos, tendo a liberdade de escolher quais os que considera mais adequados. Nesse documento devem constar, também, os critérios de avaliação, estratégias de ensino, bem como recursos didáticos e os instrumentos de avaliação.

Cada unidade curricular possui um plano de ensino e, como documentos complementares a ele, há a Situação de Aprendizagem - que possui um plano de mediação da aprendizagem e um plano de avaliação. Pôde-se observar que são planejadas Situações de Aprendizagem até que se esgotem os assuntos previstos no projeto do curso, e que se atinja o desenvolvimento das competências pretendidas.

$\mathrm{Na}$ perspectiva do proposto para a pesquisa, foram analisados os seguintes documentos: o plano de ensino, instrumentos de avaliações e materiais didáticos adotados de uma unidade curricular de cada semestre, com intuito de obter uma visão mais ampla do curso pesquisado. As unidades curriculares escolhidas foram: Fundamentos da Comunicação (100h), Processamento de Sinais (180), Manutenção de equipamentos (68h) e Dispositivos e 
Técnicas de controle (80h) como amostras, respectivamente do primeiro, segundo, terceiro e quarto semestres.

Para compreender a organização do processo educativo, analisaram-se os planos de ensino das referidas unidades curriculares, das quais, uma delas pertence ao módulo básico e as demais aos módulos específicos, de forma a garantir a fidelidade e maior amostragem do curso técnico em Automação Industrial na modalidade a distância.

Como preconizado na organização da instituição, cada unidade curricular "deve reportar-se à Unidade de Competência ou elementos que a constituem" (SENAI, 2013, p. 83). Isto levou a uma primeira percepção: a de que é essencial (como de resto para qualquer outra organização), para o desenvolvimento do curso, que toda a equipe de professores e técnicos conheça o projeto do curso, para que constantemente se autoavalie e verifique se o que está descrito no projeto do curso está realmente sendo praticado pelos professores em sala de aula, tal qual afirmam Catapan, Kassick e Otero (2011, p. 08):

[...] porque se faz necessário que fique bem claro, para todos os envolvidos no trabalho, que o objetivo último é a formação do profissional e, uma vez bem estabelecido o perfil, dele e nele, evidenciem-se as competências a serem desenvolvidas por meio das bases tecnológicas enquanto conhecimentos fundantes e necessários ao profissional, presentes no conjunto de ementas das disciplinas arroladas na sua formação. [O perfil profissional é] ponto de chegada, entendendo que, no momento da operacionalização do currículo, isto é, no processo de formação do profissional, as disciplinas e bases tecnológicas se constituem em meio para o desenvolvimento das competências que asseguram a formação profissional, e não um fim em si mesmas, evitando-se as pulverizações percebidas, geralmente, nas organizações conhecidas como grades curriculares.

Para averiguar a qualidade da educação profissional a distância desenvolvida pela instituição, as análises sobre os documentos das Situações de Aprendizagem elaboradas em cada uma das unidades curriculares selecionadas, indicam que elas parecem atender ao objetivo proposto enquanto estratégia de ensino; porém, por se tratar de uma estratégia complexa, elas foram contrastadas com o que pontua a literatura.

Quanto à concepção de uma Situação de Aprendizagem, Perrenoud (2000, p. 32) assevera que 
Karolina da Silva Cabral Clóvis Nicanor Kassick

As noções de dispositivo e de sequência didáticos chamam a atenção para o fato de que uma situação de aprendizagem não ocorre ao acaso e é engendrada por um dispositivo que coloca os alunos diante de uma tarefa a ser realizada, um projeto a fazer, um problema a resolver. Não há dispositivo geral; tudo depende da disciplina, dos conteúdos específicos, do nível dos alunos, das opções do professor. Um procedimento de projeto leva a certos dispositivos. O trabalho por meio de situação-problema leva a outros, os procedimentos da pesquisa, a outro ainda. Nesses casos, há um certo número de parâmetros que devem ser dominados para que as aprendizagens almejadas se realizem. Para entrar em mais detalhes, conviria considerar uma disciplina em particular.

Percebeu-se, nas unidades curriculares investigadas, que cada uma buscou construir sequência e atividades de acordo com os objetivos propostos que, no caso deste curso, identificam-se como as capacidades técnicas e as capacidades sociais, organizativas e metodológicas que a profissão requer, ou seja, com o perfil profissional.

Com relação às capacidades sociais, organizativas e metodológicas, constatou-se que as Situações de Aprendizagem das unidades curriculares de Processamentos de Sinais, Técnicas de Controle e Manutenção de Equipamentos negligenciaram o desenvolvimento destas capacidades. Isso ocorreu por não terem sido mencionadas em seus planos e por não explorarem, nas atividades propostas, as possíveis capacidades a serem desenvolvidas. Essas capacidades estavam mais ligadas aos procedimentos e à resolução de um problema técnico. Por conta disso, o aluno não enfrentou situações nas quais tivesse que expor sua opinião ou justificar suas escolhas para além dos aspectos técnicos.

Na própria definição de capacidades proposta pela Metodologia SENAl de Educação Profissional, fica expresso que capacidades não são inerentes aos alunos, mas passíveis de serem experimentadas em diferentes contextos e problemas; observou-se, também, a ausência ou poucas propostas de trabalhos colaborativos nas quatro unidades curriculares, uma capacidade social muito importante para o desenvolvimento do perfil profissional pretendido neste curso.

Com referência ao plano de mediação foi prevista, em todas as unidades curriculares analisadas, a estratégia de esclarecimentos de dúvidas dos conteúdos por meio de e-mail, chat (Messenger), webconferência e/ou fórum. Entretanto, como não foi possível verificar a execução dessas ações para esta pesquisa, limita-se a refletir sobre como este 
processo deve acontecer para permitir que se preserve o desenvolvimento de competências, conforme prevê a metodologia.

Para isso, faz-se necessário refletir que, ao se falar no desenvolvimento de competências em curso na modalidade EaD, está intrínseca a atitude da autonomia de estudos, reflexão e o pensamento crítico, além de outras competências específicas.

Em se tratando de um curso oferecido na modalidade a distância, o perfil do egresso considera, igualmente, o desenvolvimento de outras habilidades cognitivas, por exemplo, as experiências do mundo do trabalho, o estudo autônomo, a reflexão e o pensamento crítico (CATAPAN; KASSICK; OTERO, 2011, p. 9).

A exemplo desta prática metodológica pode-se citar a unidade curricular de Técnicas de Controle, que possui uma carga horária de $80 \mathrm{~h}$ e tem como objetivo "propiciar o desenvolvimento das capacidades técnicas, sociais, organizativas e metodológicas requeridas para a aplicação de técnicas de controle nos sistemas de controle e automação" (SENAI, 2015c, s/p). Foram organizadas três Situações de Aprendizagem para esta unidade curricular, sendo todas construídas a partir de situações-problema, para que os alunos pudessem ter contatos com situações reais possíveis de serem vivenciadas no mundo do trabalho.

Cabe enfatizar que, quando se fala em competência, que esta não se restringe somente ao saber fazer, mas ao fazer com qualidade, segurança, consciência ética e estética do que se propõe a ser feito.

No que diz respeito às competências, busca-se superar a visão estreita das abordagens que limitam o conceito de competência no âmbito exclusivo do fazer, de que competente é aquele que sabe fazer bem alguma coisa, dirigindo-a para o âmbito das dimensões do humano integrado (valores, cognição, ação), que não tem ações fragmentadas nem procede destas (CATAPAN; KASSICK; OTERO, 2011, p. 9).

O processo de ensino-aprendizagem presencial permite ao professor interagir com o aluno instantaneamente e possibilita, também, observar se aluno está consultando materiais e se está resolvendo individualmente a atividade proposta. Todavia, essa mesma situação não faz parte do ensino a distância, por isso é mister que professor elabore atividades contextualizadas e que não resultem, simplesmente, em respostas padronizadas, copiadas 
e/ou mecanizadas. Isso possibilitará uma participação qualitativa do aluno no processo de ensino-aprendizagem, mesmo que a distância.

Tão importante quanto saber perguntar é saber ouvir. Na resposta a uma pergunta bem formulada o professor tem a possibilidade de uma resposta dentro de sua expectativa. No entanto, como a pergunta será recebida e analisada dentro do contexto do desenvolvimento cognitivo e social do aluno, a resposta precisaria ser analisada dentro desse mesmo contexto e não dentro do professor. É por isso que afirmamos que a frase do professor que consideramos a mais importante e que devia ser a mais frequente em sala de aula é: "O que quis dizer com isso?". Com ela o professor daria oportunidade ao aluno de repetir de outra forma seu pensamento para detectar outros indicadores do significado que ele provavelmente estaria dando ao seu discurso (MORETTO, 2002, p. 52).

Desta forma, ressalta-se que a mediação da aprendizagem se estabelece por meio da comunicação entre o professor e aluno, seja ela presencial ou a distância. Nas palavras de Moretto (2002, p. 58), “aprender é construir significados e ensinar é oportunizar essa construção".

Especificamente no processo a distância, é fundamental que as ferramentas citadas nos planos sejam acompanhadas pelo mediador e sirvam de instrumento de comunicação frequente, pois será por meio deste mecanismo que poderá ser observada, dentre outros elementos, a avaliação processual, caso contrário, corre-se o risco de ter uma avaliação somente de produto.

A linguagem é essencial no processo de construção do conhecimento, pois é por meio dela que é possível unir os contextos, ou seja, unir aquele que o aluno traz ao que o professor está propondo. Cabe lembrar, aqui, que todos têm uma história, com vivências e experiências, antes de chegar à escola.

Para melhor compreender o assunto comecemos analisando o que chamamos de aprendizagem por acumulação. Sabemos que o sujeito faz experiências desde o nascimento, visando uma adaptação às contingências físicas e sociais que seu contexto lhe impõe. Dizemos, então, que ele se desenvolve cognitiva e socialmente. Quando chega na escola, o que pode ocorrer é um ensino realizado dentro de paradigma que favorece a acumulação de informações muitas vezes desconexas e que objetivam somente responder questões de prova. $\mathrm{O}$ aluno não tem oportunidade $\mathrm{e}$ 
nem é incitado a estabelecer relações significativas no universo simbólico que lhe é apresentado (MORETTO, 2002, p. 53).

Para que a aprendizagem seja significativa, todos os atores deste processo de ensino e de aprendizagem precisam estar cientes dos seus compromissos e das suas responsabilidades. Para Moretto (2002, p. 58, grifo do autor),

Ao aluno cabe a atividade de apropriar-se dos conhecimentos socialmente construídos e dar-Ihes significado dentro do contexto em que ele, sujeito, está inserido e também de sua estrutura conceitual. Ao professor não cabe o papel de 'transmitir' algo já pronto, mas elaborar atividades que facilitem ao aprendiz estabelecer relações significativas no universo simbólico proposto.

A base da metodologia cognitivista, em sua ramificação mais específica do ensino por competência, pressupõe a utilização do método dialético que, para Severino (2007, p. 116),

vê a reciprocidade sujeito/objeto eminentemente como uma interação social que vai se formando ao longo do tempo histórico. [Onde] o conhecimento não pode ser entendido isoladamente em relação à prática política dos homens, ou seja, nunca é questão de apenas de saber, mas também de poder. Daí priorizam a práxis humana, a ação histórica e social, guiada por uma intencionalidade que lhe dá um sentido, uma finalidade intimamente relacionada com a transformação das condições de existência da sociedade humana.

Para o autor, a dialética é uma epistemologia que possui pressupostos inerentes à condição humana e às condutas, tais como a totalidade, historicidade, complexidade, cientificidade e concreticidade.

Ainda, para Moretto (2002, p. 63),

A utilização consoante do método dialético suporta a pedagogia que estamos propondo. Em essência podemos dizer que nesse processo há uma tese estabelecida. Elabora-se uma contraposição à tese, que chamaremos de antítese. Os interlocutores deverão apresentar argumentos, buscando dirimir controvérsias e chegar a uma síntese. Esta nada mais é do que uma nova tese, que poderá encontrar uma antítese, que deverá levar a uma síntese. Esse é um processo que a história das ciências vem mostrando ao longo do tempo. É também o caminho na construção do conhecimento na 
Karolina da Silva Cabral Clóvis Nicanor Kassick

relação entre o professor e o aluno. Nesse aspecto, podemos considerar as concepções prévias do aluno como tese. O professor, em muitos pontos, mostra que a tese está baseada no senso comum e que ela apresenta contradições com o conhecimento elaborado pelas ciências e propõe a antítese. No diálogo entre os dois, o aluno chega à elaboração da síntese desejada.

No processo de comunicação entre aluno e professor, no ambiente virtual, é necessário que o educador consiga perceber que o estudante irá expressar seu pensamento dentro do contexto em que seu conhecimento foi construído e por meio de suas experiências. Nessa condição, vale ressaltar a sentença proposta por Moretto (2002, p. 68), de que "[...] todo conhecimento é uma construção individual mediada pelo social [...]".

Para que haja a ressignificação dos conceitos é necessário que o professor faça suas argumentações interagindo com o aluno. Neste caso, esbarra-se em uma relação negativa entre o professor e o erro do estudante, pois geralmente aquele não faz uma análise do motivo do erro, apenas diz se está certo ou errado. Porém, é interessante, a partir dos erros cometidos pelo aluno, que se faça, em conjunto, uma análise dos motivos pelos quais o aluno foi levado ao erro e, assim, pensar em novos caminhos de ensino para que o processo de aprendizagem se concretize.

Este procedimento e a organização do processo educativo possibilitam uma avaliação constante, logo, contínua, caracterizando-se como uma avaliação formativa e, para tanto, cabe ao professor intervir no processo de aprendizagem e interagir com o aluno, o que faz com que as avaliações não sejam o fim em si mesmas.

Belloni (2009, p. 103) reflete sobre a operacionalização do processo educativo a fim de garantir que o ele seja centrado no estudante para possibilitar o desenvolvimento da capacidade de autoaprendizagem:

A concepção de estratégias adequadas de utilização dos materiais e tecnologias de aprendizagem a distância, que são tão ou mais importantes que os próprios materiais, é fundamental para o sucesso de uma ação educacional a distância. Estas estratégias devem ser parte integrante dos materiais, tendo como objetivo promover, orientar e facilitar a aprendizagem autônoma.

\section{CONSIDERAÇÕES FINAIS}


Ao analisar este curso através das unidades curriculares mencionadas, pretendeuse contribuir com esta nova possibilidade educacional de oferta de cursos técnicos de nível médio na modalidade $\mathrm{EaD}$, também de resgatar velhos embates não superados no ensino presencial, como planejamento, objetivos educacionais, práticas pedagógicas, mediação da aprendizagem, escolha de estratégias eficientes e avaliação. Esses são assuntos antigos, ainda muito discutidos e pouco alterados efetivamente na prática, tanto na modalidade presencial quanto na modalidade a distância, seja no ensino regular e/ou no ensino profissionalizante.

O exercício da docência e os questionamentos a respeito das novas competências do professor, sua formação inicial e a formação continuada são questões que não podem ser caladas, precisam ser discutidas no meio acadêmico e também consolidadas na prática docente.

Entende-se, para isso, a necessidade de inovação, de trabalhos colaborativos e projetos que possam levar sucesso à jornada educacional. Mais do que nunca, as ferramentas tecnológicas de comunicação tornaram-se essenciais na vida das pessoas para a viabilização dessa nova modalidade de ensino.

Considera-se, também, que os cursos profissionalizantes de nível médio na modalidade EaD podem proporcionar uma aprendizagem efetiva, desde que partindo de um alinhamento entre a organização do processo pedagógico com bases teórico-cognitivistas. Igualmente, faz-se necessário que possuam foco na formação humanística/cidadã, além da qualidade técnica. Compreende-se, por fim, que esta é uma prática possível, conforme se pôde verificar através das escolhas didático-pedagógicas presentes nos planos de ensino das unidades curriculares do curso técnico de Automação Industrial na modalidade EaD do SENAI/SC.

Sabe-se que todo e qualquer trabalho científico não tem por objetivo esgotar sua temática, e este não é diferente. Fica, deste estudo, o sentimento de que há outros aspectos acerca da educação a serem investigados, de forma a contribuir para que se possa continuar a perseguir o ideal de uma educação profissional de nível médio de qualidade para todos, tal qual preconizado pela meta 11 do PNE 2014-2024. 


\section{REFERÊNCIAS}

ABED. Associação Brasileira de Educação a Distância. 2014 Censo EAD.BR. Relatório Analítico da Aprendizagem a Distância no Brasil. Curitiba: Ibpex, 2015.

Disponível em: <http://www.abed.org.br/censoead2014/CensoEAD2014 portugues.pdf>. Acesso em: 04 nov. 2015.

ALVES, J. R. M. A história da EAD no Brasil. In: LITTO, F. M.; FORMIGA, M. (Org.). Educação a distância: o estado da arte. São Paulo (SP): Pearson Prentice Hall, 2009. xv. p. 9-13.

BELLONI, M. L. Educação a distância. 5. ed. 1ạ reimpressão. Campinas, SP: Autores Associados, 2009.

BRASIL. Lei no 9.394, de 20 de dezembro de 1996. Estabelece as diretrizes e bases da educação nacional. Disponível em: <http://www.planalto.gov.br/ccivil 03/LEIS/L9394.htm>. Acesso em: 24 abr. 2015.

. Ministério da Educação. Secretaria de Educação Superior. Disponível em: $<$ http://portal.mec.gov.br/sesu/arquivos/pdf/nova/acs portaria4059.pdf >.2004>. Acesso em: 28 set. 2015.

. Ministério da Educação. Projeto de Lei no de 2010. Estabelece o Plano Nacional de Educação - PNE para o decênio 2011-2020, e dá outras providências. Disponível em: <http://portal.mec.gov.br/index.php?option=com docman\&view=download\&alias=711 6-pl-pne-2011-2020\&ltemid=30192>2010> . Acesso em: 01 abr. 2016.

Decreto no 5.154 de 23 de julho de 2004. Disponível em: <http://www.planalto.gov.br/ccivil 03/ Ato2004-2006/2004/Decreto/D5154.htm\#art9>. Acesso em: 05 fev. 2016.

CATAPAN, A. H.; KASSICK, C. N.; OTERO, W. R. I. Currículo referência para o sistema e-Tec Brasil - uma construção coletiva. 2011. Disponível em: <http://www.etec.ufsc.br/file.php/1/cr/pretextos/3.html>. Acesso em: 20 ago. 2015.

GOMES, S. G. S. Políticas públicas em EAD no Brasil. 2015. Disponível em: $<$ http://ftp.comprasnet.se.gov.br/sead/licitacoes/Pregoes2011/PE091/Anexos/Eventos mo dulo 1/topico ead/Aula 04.pdf>. Acesso em: 28 set. 2015.

MARTINS, L. A formação social da personalidade do professor: um enfoque vigotskiano. 1. ed. Campinas: Autores Associados, 2007.

MORETTO, V. P. Prova um momento privilegiado de estudo e não um acerto de contas. 2. ed. Rio de Janeiro: DP\&A, 2002.

OBSERVATÓRIO PNE. Disponível em: <http://www.observatoriodopne.org.br/metas-pne/11educacao-profissional>. Acesso em: 02 fev. 2015. 
PELIZZARI, A.; KRIEGL, M. d. L., BARON, M. P., FINCK, N. T. L. e DAROCINSKI, S. I. . Teoria da aprendizagem significativa segundo Ausubel. Rev. PEC, Curitiba, v. 2, n. 1, p. 37-42, jul. 2001jul. 2002.Disponível em: <http://portaldoprofessor.mec.gov.br/storage/materiais/0000012381.pdf>. Acesso em: 02 dez. 2015.

PERRENOUD, P. 10 novas competências para ensinar. Porto Alegre: Artmed Editora, 2000.

SENAI. Serviço Nacional de Aprendizagem Industrial. Projeto de autorização de funcionamento de curso técnico e credenciamento de unidade de ensino para a oferta de educação profissional técnica de nível médio na modalidade a distância. Autorizado pela Resolução do Conselho Regional do SENAI/SC no 64/2012. Credenciada para a oferta de educação profissional técnica de nível médio na modalidade presencial pelo Parecer do Conselho Estadual de Educação do Estado de Santa Catarina no 333/2002. Florianópolis, 2012.

Serviço Nacional de Aprendizagem Industrial. Departamento Nacional.

Metodologia SENAI de educação profissional. Brasília: SENAI/DN, 2013.

. Serviço Nacional de Aprendizagem Industrial. Documento interno

intitulado Campanha Cursos Técnicos EAD 2015, publicado na intranet da instituição, 2015a.

. Serviço Nacional de Aprendizagem Industrial. Plano de Ensino: Fundamentos de Comunicação. Florianópolis, 2015b.

. Serviço Nacional de Aprendizagem Industrial. Plano de Ensino: Técnicas de Controle, Florianópolis, 2015c.

SEVERINO, J. S. Metodologia do trabalho científico. São Paulo - SP: Cortez, 2007.

RECEBIDO EM 28 DE SETEMBRO DE 2016.

APROVADO EM 31 DE OUTUBRO DE 2016. 